\title{
Para um estudo psicológico das virtudes morais
}

Yves de La Taille

Universidade de São Paulo

Resumo

0 propósito deste artigo é defender a importância de estudos psicológicos das virtudes morais (como generosidade, coragem, humildade, fidelidade etc.). Tal defesa é realizada de várias formas.

Do ponto de vista filosófico, o tema das virtudes não somente é clássico (Ver Aristóteles, por exemplo) como tem sido rediscutido por autores contemporâneos descontentes com as limitações da ética moderna, em geral baseada no conceito de direito. Do ponto de vista psicológico, 0 autor defende a idéia segundo a qual as virtudes morais não somente participam da gênese da moralidade, como representam traços de caráter essenciais à coesão da personalidade moral.

Tal perspectiva está, de certa forma, anunciada na obra de Piaget sobre o juízo moral, como em autores outros como Tugendhat. Ela está também presente nos estudos sobre a relação entre o sentimento de vergonha e a ética.

Finalmente, aponta-se que, no que se refere à educação moral, as virtudes podem representar um tema rico e sugestivo para a reflexão das crianças e adolescentes.

P alavras-chave

Moral - Virtudes - Desenvolvimento - Caráter. 


\section{For a psychological study of moral virtues}

Yves de La Taille

Universidade de São Paulo

\section{Abstract}

The purpose of this article is to advocate the importance of psychological studies of the moral virtues (such as generosity, courage, modesty, faithfulness, etc.). This argument is proposed by several ways.

From the philosophical viewpoint, the theme of virtues is not only classical (see Aristotle, for example), but has been revisited by contemporary authors dissatisfied with the limitations of modern ethics, largely based on the concept of rights.

From the psychological point of view, the author defends the idea that moral virtues not only participate in the genesis of morality, but also represent essential features of character to the cohesion of the moral personality.

Such perspective is, to some extent, announced in Piaget's work about moral judgement, as well as by other authors such as Tugendhat. The same perspective is also presented in studies on the relationship between ethics and the feeling of shame.

Finally, it is remarked that, in what concerns moral education, the virtues can be a rich and suggestive topic for reflection by children and adolescents.

Keyw ords

Moral - Virtues - Development - Character. 
Acreditamos que é possível defender a importância de pesquisas sobre as virtudes morais de três formas diferentes e complementares: 1) 0 interesse universal do tema; 2) sua inserção numa possível definição do que seja moral ou ética; e 3) sua relevância psicológica na construção da moral por parte do ser humano em geral e da criança em particular. Vamos desenvolver cada uma dessas razões, que nos levam a eleger as virtudes morais como objeto de investigação da psicologia do desenvolvimento.

\section{Tema universal}

1) Existirá uma cultura na qual características humanas como coragem, fidelidade, prudência e outras não sejam identificadas, nomeadas e apreciadas? A resposta cabe à Antropologia, e a resposta desta certamente é negativa. Nas diversas literaturas, filosofias e religiões, encontram-se referências a elas. $\mathrm{Na-}$ turalmente, em diversas culturas ou em diversos momentos históricos tais características humanas podem receber um tratamento diferente. 0 que era visto como coragem pelo cavaleiro feudal (arriscar-se em duelos, por exemplo), pode ser visto como temeridade e falta de humildade para um pai de família contemporâneo; e o que é visto como prudência política para um social- democrata, pode ser interpretado como covardia para um revolucionário comunista. Porém, o fato de haver sérias discordâncias a respeito do que é a verdadeira expressão da coragem, da prudência ou da humildade, longe de depor contra a importância humana do tema, pelo contrário, a reforça. Parece que cada cultura em geral e cada indivíduo em particular sentem a necessidade de pensar e julgar tais características humanas que respondem pelo nome de virtudes. Portanto, não é a presença ou a ausência do pensar sobre virtudes que diferencia pessoas ou culturas, mas sim a qualidade desse pensar. Assim como a racionalidade e a moral, o tema das virtudes é universal. Tanto é verdade que, nas conversas do cotidiano, elas estão presentes, e isso ocorre não somente entre os adultos, mas também entre as crianças. Com efeito, nossas pesquisas anteriores atestaram o fato de as crianças pequenas, mesmo com o desconhecimento da palavra que as nomeia, terem opiniões sobre se devemos ou não dar publicidade a nossos feitos (humildade), se devemos ou não ceder nossa fruta predileta a um irmão (generosidade), se o tamanho de um desafio é medida para a coragem, etc. (La Taille e outros, 1998).

Em resumo, não nos parece exagerado dizer que encontramos nas virtudes um tema propriamente humano, um tema universal. Só este fato, pensamos, justificaria inúmeras pesquisas.

Podemos nos perguntar por que esse tema tem tanta relevância para o homem. Vemos três razões para o fato.

2) A primeira decorre da própria definição geral da palavra virtude: qualidade própria para que se produzam certos efeitos, característica, propriedade (Dicionários Lexis e Aurélio). De acordo com esta definição, a virtude da faca é cortar e a do olho é enxergar. Numa definição mais restrita, e mais freqüente, a palavra virtude refere-se a qualidades das pessoas. Trata-se, portanto, de um juízo de valor feito sobre um indivíduo. Ora, sendo que as representações de si, que formam a identidade de cada pessoa, são sempre valorativas (ver Taylor,1998; Perron, 1991; Adler, 1992; La Taille, 2000), é fácil compreender por que as virtudes são de suma importância para os homens: pelo fato de elas possibilitarem a todo homem uma leitura valorativa de si próprio e dos outros, elas fazem parte do quadro de referências a partir do qual cada um se entende como ser humano.

3) A segunda razão complementa a primeira: não somente as virtudes incidem sobre qualidades de cada pessoa, como elas apontam para qualidades apreciadas, admiradas 
até. E são almejadas também. Mais ainda: apontam para a excelência, para um ideal. Como pensava Aristóteles, a pessoa virtuosa não é somente aquela que age bem, mas sim aquela que quer o bem e, assim, é uma "boa pessoa" (ver também Tugendhat, 1993). Escreveu o Estagirita:

Não se poderia dizer de um homem que é justo se ele não experimenta a alegria de ações justas, e nem que um homem é generoso se não tem prazer na ações generosas, e assim por diante. Assim, devemos convir que as ações conforme a virtude são agradáveis em si. (Aristóteles, 1965, p. 36)

Logo, as virtudes não somente remetem a uma leitura valorativa da pessoa humana (assim como os vícios), como referem-se a qualidades desejadas.

Mas desejáveis de que ponto de vista: do prazer? da felicidade? da ética? Isso nos leva à terceira razão pela qual as virtudes têm relevância do ponto de vista humano: sua referência à ética.

4) Se pensamos em prazer no sentido físico ou imediatista da palavra, é claro que as virtudes pouco ou nada têm a ver com essa experiência humana. M as se pensarmos num uso equilibrado e harmonioso dos prazeres, aí sim as virtudes podem ser evocadas, notadamente a temperança. Mas o que legitimaria a busca de tal equilíbrio e harmonia? Ora, a felicidade. Essa é a posição de Aristóteles e sua teoria nos leva justamente a levantar a dimensão ética. Como se sabe, para o filósofo grego, a Ética define-se pela busca da felicidade (eudemonismo). Portanto, deste ponto de vista, as virtudes não somente têm relevância humana por referirem-se a valores desejáveis, como adentram no universo moral: elas definem o caráter de uma pessoa e, por caráter, deve-se entender uma avaliação ética da personalidade. A esse respeito escreveu judiciosamente Sennett:
Os antigos anglofônicos, e na verdade os escritores que remontam à Antigüidade, não tinham dúvidas sobre o significado de caráter: é 0 valor ético que atribuímos aos nossos próprios desejos e às nossas relações com os outros. Horácio descreve que o caráter de al guém depende de suas ligações com o mundo. Neste sentido, caráter é um termo mais abrangente que seu rebento mais moderno personalidade, pois este se refere a desejos e sentimentos que podem apostemar por dentro, sem que ninguém veja. (1999, p.10 - grifo nosso)

Aristóteles também emprega o conceito de caráter, não para julgar se alguém é inteligente ou apaixonado, mas sim se é "generoso", "temperante" (1965, p.47). Dissemos que o conceito de caráter corresponde a uma leitura ética da personalidade. Isso é válido no senso comum: quando se diz de alguém que tem caráter, trata-se de um elogio; o que também é valido para a ética: quando se diz de uma pessoa que é justa (e justiça é uma virtude), está se fazendo uma avaliação a partir de um valor ético. ${ }^{1}$

1. 0 fato de a Ciência Psicológica empregar a palavra personalidade para definir um campo de pesquisa é compreensível: ela precisa tender à neutralidade. Assim, dizer de uma pessoa que ela é obsessiva ou paranóica é remeter-se a traços psicológicos razoavelmente precisos que não dizem respeito ao certo ou ao errado. Curiosamente, tais conceitos psicológicos têm adentrado a linguagem do dia-a-dia (essencialmente entre as pessoas razoavelmente cultas), fato que permite a certas pessoas serem mais tolerantes em relação a si próprias e aos outros. Mas note-se aqui que tais conceitos da personalidade costumam tomar 0 lugar dos vícios. Assim, ao invés de acusar alguém de covardia, compreender-se-á sua inconstância e fragilidade egóicas. Em compensação, traços como coragem e generosidade continuam sendo assim chamados e admirados. Talvez pelo fato de as teorias de personalidade terem nascido da clínica, os problemas (em geral características pouco admiráveis e facilmente associadas a fraquezas de caráter, portanto desprezíveis), os chamados vícios têm sido nomeados de forma mais neutra, o mesmo não acontecendo com as virtudes. Além do mais, faz sentido alguém procurar uma terapia por achar-se muito medroso ou egoísta (mas preocupar-se com o fato, já demonstra a virtual presença das virtudes associadas) do que por preocupar-se com sua coragem e generosidade. Para finalizar, note-se também que alguns estudos de personalidade têm como motivo uma leitura valorativa das condutas humanas, como por exemplo, o estudo de Adorno sobre a Personalidade Autoritária (1950). 
Em resumo, as virtudes remetem-nos a dimensões universais, pois essencialmente humanas, a saber: qualidade atribuída à pessoa, valor desejável e admirável, leitura ética da personalidade. Pensamos que isso já basta para avalizar um estudo psicológico das virtudes.

Todavia, ainda falta escolher em que campo da Psicologia vamos realizar tais investigações. Um campo que nos parece adequado é 0 das Representações Sociais. De fato, por que não eleger algumas virtudes e verificar que significações e valores são a elas associadas por determinados grupos sociais? Outro campo da Psicologia que também parece colocar-se, notadamente em razão do que foi acima exposto, é o da Psicologia Moral. Com efeito, se as virtudes permitem uma leitura ética da personalidade, seu estudo pode, em aparência, perfeitamente integrar-se a este clássico campo da Psicologia. No entanto, as coisas não são tão simples assim, não só porque nem todos os pesquisadores dessa área são seguidores de Aristóteles! Longe disso aliás, pois são, em sua maioria, kantianos, fato que explica a quase inexistência de pesquisas sobre virtudes outras que a justiça. É sobre essa difícil relação entre virtudes e ética que vamos nos debruçar agora.

Virtudes e étic a: axiologia

5) 0 leitor terá reparado que colocamos no título de nosso texto o adjetivo moral para qualificar as virtudes que vamos estudar. Nada mais fizemos do que seguir Aristóteles, que faz uma distinção entre virtudes intelectuais (como a inteligência) e as morais (como a generosidade e a temperança). Vimos que o conceito de caráter corresponde a tais virtudes morais. Mas alguém poderá dizer que o emprego do adjetivo moral é abusivo. Por exemplo, uma pessoa pode ser corajosa (é um traço de caráter) e por essa razão aceitar arriscar-se em atos terroristas: neste caso, a coragem é uma virtude moral? Pelo menos do ponto de vista de quem condena sacrificar inocentes em nome de que causa for, tal coragem não será moral, será imoral. Outro exemplo, sempre com a mesma virtude: todo mundo concordará que em geral é preciso coragem para reagir a humilhações praticadas por pessoas poderosas (imaginemos um aluno que reaja à humilhações de um professor), e certamente todo mundo (menos 0 agressor! ${ }^{2}$ ) admirará tal determinação e reconhecerá no valente combatente uma pessoa de caráter. No entanto, uma vez que defender-se de humilhações é seguir seu próprio interesse, não sendo portanto uma atitude altruísta, poder-se-á dizer que, embora admirável, não se trata de uma ação moral. A coragem para defender outrem de humilhações, esta sim seria uma atitude moral. Em suma, a coragem em si nada teria de moral e, portanto, chamá-la de virtude moral traduziria uma generalização indevida e perigosa. E, seguindo este raciocínio, a única virtude que realmente mereceria o referido adjetivo seria a justiça: como dizia o próprio Aristóteles, ela é sempre boa. Nela, forma e conteúdo fundem-se.

Ora, esta tem sido a posição da Psicologia Moral: eleger a justiça como objeto de seus estudos e, como o fez Turiel (1993), definir em torno dela (justice and fairness) 0 domínio moral. 0 resto pertenceria ao domínio convencional (ritos religiosos, por exemplo) ou ao domínio pessoal (beber Coca-Cola ou Guaraná). Em suma, não podemos propor um estudo das virtudes dentro do campo da Psicologia Moral sem nos debruçar sobre 0 obj eto de estudo dessa área do conhecimento. Tal objeto deve ser abordado de duas formas: a axiológica e a causal (ver Piaget, 1965). Comecemos pela dimensão axiológica e voltemos, portanto, à definição do que é moral (ou ética, ambos os conceitos sendo aqui empregados como sinônimos).

2. E mesmo este pode, secretamente, admirar seu inesperado rival. 
6) Tugendhat, em suas Lições sobre ética, lembra que "o conceito de virtude foi por muito tempo deixado de lado pela éticas modernas" (1993, p. 243). Cremos que a ausência das virtudes nas reflexões modernas da Ética deve-se ao conceito de direito moral.

Escreve o mesmo autor que "respeitar alguém significa reconhecê-lo como sujeito de direitos morais" (p.391). 0 próprio autor sublinha que tal definição básica do respeito é problemática: mais elementos estariam presentes. Mas o fato é que o marco zero (ou mínimo denominador comum) do respeito é aquele derivado do reconhecimento do outro como possuindo direitos. Por exemplo, como todo ser humano tem direito à integridade física e psicológica, é moral tratá-lo respeitando seu corpo e sua mente (por mais que seja um facínora). Outro exemplo, como todo ser humano tem direito a ser julgado segundo a Lei, e que esta vale para todos, é moral julgá-lo sem privilégios ou sem severidade singular. Os Direitos Humanos representam certamente a forma mais elaborada dos direitos morais inspirados na máxima kantiana: devemos sempre tratar 0 homem como um fim (é o seu direito) e nunca como meio (o que iria de encontro ao imperativo categórico moral).

Isto posto, verifica-se que dos direitos morais decorrem deveres morais (mas a recíproca não é verdadeira, como veremos mais abaixo). Trata-se de pura lógica: se é reconhecido a alguém um direito, os outros têm o dever de respeitá-10. Ora, entre as virtudes, apenas uma parece-nos corresponder ao binômio direito/deveres: a justiça. Sendo imperativo que é um direito de cada um ser tratado de forma justa, é também imperativo que cada um aja de forma justa, ou que pelo menos procure pautar suas ações no ideal de justiça. Daí resultar uma moral de regras (que podem ser inúmeras e sempre por ser criadas): os deveres traduzem-se em regras de conduta que podem ser formuladas com razoável clareza. É claro que pode haver conflitos entre os próprios direitos e de- veres decorrentes. Lembremos o clássico dilema de Heinz, formulado por Kohlberg: deve, ou não, um homem pobre roubar um remédio de preço inacessível para salvar sua mulher da morte? Entre outros elementos (como a legalidade, a vida privada, a harmonia social etc.), tal dilema apresenta um conflito entre o direito à propriedade privada (a do farmacêutico, inventor e dono do remédio) e o direito à vida (a da mulher gravemente enferma). Mas seja qual for a solução dada, pela própria formulação do dilema, sempre prevalecerá um direito e o dever dele derivado.

Antes de refletirmos sobre demais virtudes, devemos verificar que as pesquisas em Psicologia Moral têm se limitado a esta definição de moral: são morais as condutas que respeitam o direito alheio e o juízo que o considere. Mesmo sem remeter-se explicitamente a essa definição, Piaget (1932) considera a moral como um conjunto de regras, e as histórias às quais os sujeitos são submetidos tratam de roubo (direito à propriedade), de mentira (direito à verdade), de justiça retributiva e distributiva (direito a ser tratado a partir do ideal de igualdade e eqüidade). Em relação a Kohlberg (1981), basta lembrar que ele mesmo coloca a justiça como eixo de toda moral e que, segundo ele, esta não pode ser definida como um "saco de virtudes". E Turiel, como vimos acima, define o domínio moral como referente à justiça e com regras que são julgadas como universais pois correspondem a direitos de toda e qualquer pessoa. A voz destoante na Psicologia (pelo menos a mais conhecida) é a de Carol Gilligan $(1982,1988)$ que, ao lado da ética da justiça, propõe a existência de outra, tão importante quanto, segundo ela: a do cuidado (care). Ora, a referida ética do cuidado remete-nos a outra virtude: a da generosidade (para maior análise das relações entre cuidado e generosidade, ver La Taille, 2000).

7) Dificilmente alguém não julgará como moralmente admirável atos de genero- 
sidade. Todavia, por definição, o ato generoso merece esse nome porque não corresponde a um direito da pessoa contemplada. Fosse um direito, não se trataria de generosidade, mas sim de justiça. Por exemplo, se ajudamos um amigo em dificuldades financeiras, não é porque é um direito de cada um receber a ajuda de outrem, mas sim porque achamos certo fa zê- $10 .{ }^{3} \mathrm{~A}$ pessoa generosa pode ser movida por um sentimento de dever: para ela é obrigatório conduzir-se com generosidade. Mas tal dever não é derivado de um direito alheio, mas sim do valor moral da virtude em questão. Vale dizer que a generosidade traduz um respeito pelo próximo, mas este não é, no caso, um sujeito de direitos. Mas, então, a generosidade é moral? Tomemos outra virtude: a gratidão. 0 reconhecimento espiritual de uma dívida é sem dúvida considerado como um bem pela maioria das pessoas, mas - assim como a generosidade, e mais claramente que esta - a ela não corresponde nenhum direito (aliás, dizer que há um direito em receber a gratidão de outrem chegaria a aniquilar o valor dessa virtude: ou ela é espontânea, ou ela não é). A gratidão é, portanto, moral?

Alguém poderá responder aqui que todo e qualquer ato altruísta é moral. Assim, o respeito moral receberia um definição mais ampla, e não vinculada apenas a direitos. Respeitar moralmente uma pessoa seria traduzido por trazer-Ihe algo, seja algo que é um direito seu, seja algo que Ihe falta, seja ainda algo que the dê prazer ou traga felicidade. Mas tal ampliação apresenta dois tipos de problemas.

O primeiro: ao identificar altruísmo e moral, os domínios pessoal e moral interpenetram-se. Aqui é a teoria de Turiel que está em jogo. Tivemos a feliz oportunidade de conversar recentemente 4 com Larry Nucci, grande divulgador da Teoria dos Domínios, e de Ihe perguntar em que domínio ele colocava a virtude generosidade. E ele nos respondeu que, por um lado, em razão de 0 ato generoso depender de uma decisão livre do sujeito (no sentido de que ninguém é obrigado por outrem ou pela sociedade - pelo menos de direito - a ser generoso), a virtude correspondente pertencia ao domínio pessoal; e que, por outro, em razão de este ato beneficiar alguém, a generosidade também pertencia ao domínio moral. Tal resposta, com a qual concordamos, traz duas decorrências teóricas importantes. Em primeiro lugar, torna complexa a definição do domínio pessoal. De fato, nele costumam ser colocadas condutas anódinas, como escolher a marca de pasta de dentes, arrumar ou não 0 próprio quarto, ou escolher parceiros sentimentais. Ora, se cabem também nesse domínio, por dependerem de decisão totalmente individual, algumas condutas virtuosas, ele ganha uma nobreza social sobre a qual vale a pena se debruçar. $E$ isso nos leva à segunda decorrência teórica: se algumas condutas, embora pertencentes ao domínio pessoal, também pertencem ao domínio moral, não há razão para que a Psicologia deva se limitar a estudar apenas as condutas exclusivamente pertencentes ao domínio moral. Seria empobrecê-lo. E, por conseguinte, estamos autorizados não só a estudar as virtudes altruístas (ou pró-sociais) como a generosidade e a gratidão, já citadas, como também a compaixão, a fidelidade, 0 amor, e outras mais. Em resumo, se, com Nucci, admitirmos que merecem o nome de moral não apenas as condutas determinadas por direitos alheios mas também todas aquelas que beneficiam outrem, 0 campo da Psicologia Moral amplia-se e não há mais razão para eleger a virtude justiça como a única digna de estudo. Pode ser a mais importante, mas não a única.

3. Às vezes, mesmo neste caso, diz-se que é justo ajudar um amigo, mas aqui a palavra justo significa certo e não remete, portanto, ao ideal de justiça. Em francês, diz-se que uma idéia é justa quando corresponde à realidade, prova da sinonímia possível entre justo e certo ou correto.

4. Foi durante o III Congresso Brasileiro de Psicologia do Desenvolvimento, que aconteceu na cidade de Niterói (RJ ), no mês de julho de 2000. 
Vejamos agora o segundo problema que traz uma definição de moral que contém exclusivamente condutas altruístas. Que a generosidade seja altruísta, não há dúvidas: com ela, age-se exclusivamente por amor ao próximo, e 0 indivíduo generoso em nada se beneficia materialmente de seu ato (pode experimentar prazer ou felicidade em ser generoso, o que é diferente de uma retribuição social). Mesma coisa pode-se dizer da gratidão e do amor (colocado como virtude por Comte-Sponville, 1995). Não há interesse em ser grato, amoroso ou generoso. E se houver, significa que não houve nem amor nem gratidão nem generosidade. Perguntemo-nos agora se a justiça é genuinamente altruísta. A resposta é negativa pelo simples fato de 0 ato de justiça beneficiar tanto quem é justo como quem é objeto da justiça. Por exemplo, se somos justos com um aluno, é claro que o benefício imediato é dele. Porém, virtualmente, também nos beneficiamos porque é de nosso interesse que a sociedade seja regida por regras justas. Dito de outra forma, na justiça não é a particularidade de outrem que está em jogo, não é o desprendimento (como no caso da generosidade), mas sim a reciprocidade, vale dizer, o contrato. Assim, faz sentido alguém ao mesmo tempo sentir-se no dever de ser justo e no direito de exigir que o tratem justamente. Não faz tanto sentido alguém sentir-se no dever de ser generoso ou grato ou, ao mesmo tempo, exigir que 0 tratem generosamente e com gratidão. Em uma palavra, o fato de a justiça conferir direitos retira- Ihe o caráter puramente altruísta. É melhor dizer que a justiça (e talvez a fidelidade) pertence a uma definição contratual de moral (como o fez Piaget).

8) Se 0 que acabamos de analisar fizer sentido, temos uma primeira autorização teórica para incluir outras virtudes, além da justiça, no campo da Psicologia Moral. E como problematizamos tanto a exclusividade da definição contratual da moral (o domínio moral, com re- gras e deveres decorrentes de direitos) quanto a exclusividade da definição altruísta (que corresponderia mais ao domínio pessoal), somos, num primeiro momento, levados a eleger o conceito de relação social como organizador do que podemos chamar de moral. Assim, todas as virtudes que, por altruísmo ou por contrato, dizem respeito ao outro são merecedoras de estudos psicológicos. É o caso, por exemplo, da justiça, da generosidade, da gratidão, da fidelidade, da tolerância, da polidez. Todas elas são, segundo a expressão inglesa, other-regarding e, se algumas traduzem-se por regras, outras são traduzidas apenas por atitudes (é o complemento que quer fazer Tugendhat à ética moderna).

E as outras, como a humildade, a coragem, a prudência, o humor e a temperança? Numa definição other-regarding da moral, elas não têm lugar, a não ser vinculadas a relações sociais (por exemplo, ser corajoso para salvar uma pessoa). Não seriam, portanto, virtudes morais em si, e deveriam ser deixadas de lado pelo psicólogo interessado pela moral humana.

Todavia, seria precipitação chegar a essa conclusão. Tomemos o exemplo do dilema de Heinz. Uma coisa é ser colocado no papel de juiz e avaliar se Heinz agiu bem ao roubar o remédio para salvar sua mulher. Concordamos com Kohlberg: a virtude justiça, nesse caso, domina a cena. Mas agora façamos a pergunta que muita gente já se fez: será que um sujeito, classificado como pós-convencional na entrevista e que, por conseguinte, apoiaria a decisão de Heinz por considerá-la justa, agiria como Heinz?

Tal pergunta costuma ser feita para suspeitar da possível desvinculação entre juízo e ação, notadamente em relação à chamada dupla moral. Mas nossa pergunta aqui é diferente. Vamos imaginar alguém plena e honestamente convencido de que 0 moralmente certo é roubar o remédio e que, em situação semelhante, não o faz porque tem medo. 
Medo do quê? Por exemplo, medo da polícia (em certos países, truculenta) ou medo de ficar preso. Nesse caso, deveras bem humano, é preciso que nosso protagonista esteja não somente convencido do caráter justo do roubo como tenha outra virtude, a coragem. É claro que, nesse exemplo, o valor moral da coragem deve-se ao fato de esta virtude estar associada à justiça. Mas o que queremos frisar é que, sem tal virtude, a justiça não se tornaria ato e, portanto, não existiria: o medroso, abandonando 0 plano de roubar o remédio e assim abandonando a mulher à morte, agiria de forma não justa, e provavelmente sentiria culpa e vergonha. Em suma, parece-nos que a coragem apresenta-se às vezes como condição necessária da ação ética e, por conseguinte, tem relevância moral. Seríamos tentados a dizer que se não houvesse pessoas corajosas, a ética humana seria outra, ou, aliás, não seria. Com efeito, não raras são as vezes em que o agir moral leva a riscos e é provável que se não tivesse existido pessoas como Martin Luter King, Gandhi, e outros chamados heróis da luta pela justiça, a própria justiça seria um ideal ético enfraquecido. Mesma coisa pode ser dita da humildade. Sabe-se que existe correlação entre a chamada "personalidade autoritária", em geral intolerante e injusta, e traços de narcisismo. Ora, a humildade é justamente a virtude referente às tendências à vaidade, ao orgulho, à honra etc. Se o termo narcisismo é oriundo da clínica, pode-se dizer, do ponto de vista moral, que a ausência da virtude humildade não somente pode acarretar sofrimentos para a própria pessoa como pode levar a ações imorais. Assim, pensamos que até mesmo virtudes auto-referenciadas (selfregarding) devem ser contempladas pela Ética.

9) Mas alguém poderá aqui insistir e dizer que tanto a coragem como a humildade podem se revestir de caráter moral apenas se vinculadas à justiça ou à generosidade. E o que queremos afirmar é, em primeiro lugar, que, se elas aparecem às vezes como condição necessária ao agir ético, elas não podem, sem mais nem menos, ser desprezadas pela Filosofia e Psicologia Morais. E, em segundo lugar, queremos dizer que elas podem trazer dimensões morais próprias, nada desprezíveis. Pensemos no exemplo a seguir.

Uma pessoa $X$ bate (gratuitamente) em outra pessoa $Y$. Os conceitos de justiça e bem-estar bastam para condenar $\mathrm{X}$ : como é um direito de $Y$ ser tratado de forma respeitosa, é dever de $X$ abster-se da violência. Em uma palavra, $X$ age mal porque viola um direito de $Y$. Imaginemos agora que $X$ seja um adulto e $Y$, uma criança. Este fato nada muda do ponto de vista dos direitos de $Y$ e dos deveres de $X$. No entanto, veremos em $X$, além de uma conduta injusta, uma conduta covarde (o oposto da coragem). Será tal covardia irrelevante do ponto de vista moral? Não acreditamos, como não acreditamos que as pessoas, em geral, pensem apenas nos direitos de $Y$. Mas este último diagnóstico é psicológico, o que nos leva a encetar a outra forma de defender um estudo das virtudes morais: o lugar destas na explicação psicológica do fenômeno da moralidade.

Virtudes e ética: explic ação psic ológic a

10) Mesmo que a Ética restrinja a definição de moral a um conjunto de regras derivadas de direitos e deveres, isto ainda não autoriza o psicólogo da moralidade humana a apenas debruçar-se sobre a virtude justiça. Os argumentos colocados nos dois parágrafos anteriores podem ser retomados aqui. Se é verdade que virtudes como coragem e humildade são, às vezes, condições necessárias ao agir com justiça, então o psicólogo não pode não ter o que dizer a respeito das características de personalidade (caráter) que as definem. Tal nos parece ser um excelente motivo para que a Psicologia Moral cesse de se limitar a estudar como crianças e adultos julgam 
direitos e deveres. Mais ainda, se tivermos razão em afirmar que um ato covarde de injustiça traz dimensões outras que a injustiça por si só, e se também tivermos razão em afirmar que, para a maioria das pessoas, tais dimensões têm relevância moral, cabe ao psicólogo, não somente comprovar o fato, como melhor compreender que lugar ocupam virtudes como coragem e humildade no universo moral dos indivíduos. Ora, quase nada sabemos sobre esse lugar, como sobre o lugar das outras virtudes, mesmo as altruístas como generosidade e gratidão. Segundo Flanagan: "Ignoramos, do ponto de vista psicológico, o que é uma virtude" (1996, p.15). Pensamos que está na hora de preencher esta lacuna.

Uma outra maneira de defender a hipótese de que as virtudes devem compor o campo da Psicologia Moral é pensarmos a partir da perspectiva genética.

11) Reflitamos sobre a seguinte citação, extraída do Le Jugement Moral de Piaget: “É quando a criança habitua-se a agir do ponto de vista dos próximos, e preocupa-se mais em agradá-los do que a eles obedecer, que ela chega a julgar em função das intenções" (1932. p.105). Esta frase traz um ponto clássico da perspectiva piagetiana: a passagem de uma moral da obediência (nome que também designa a heteronomia) para outra, superior, que leva em conta as intenções dos agentes, a moral autônoma, na qual o realismo moral é superado. Mas a citação traz mais do que isso. Por um lado, refere-se a uma explicação causal para dar conta da evolução moral. Por outro, e é os que nos interessa aqui, nela está afirmado que o que explica a passagem da heteronomia para a autonomia não é tanto uma tomada de consciência do outro como sujeito de direitos, mas antes a tendência a considerá-lo na sua singularidade: é o que sugere 0 emprego do verbo agradar (faire plaisir). Em uma palavra, Piaget nos fala mais, nesta citação, em generosidade do que em justiça, embora, na sua própria teoria, a autonomia representa a vitória do princípio de justiça sobre a mera obediência à autoridade. Vale dizer que podemos levantar a hipótese de que, no caminho para a construção do ideal de justiça, a generosidade (e outras virtudes altruístas, que levam em conta o outro na sua especificidade) desempenha um papel. $\mathrm{Na}$ autonomia (sobretudo como definida por Kohlberg), a justiça precederá, do ponto de vista lógico (implicações), à generosidade, mas esta talvez preceda à justiça, moralmente falando, do ponto de vista cronológico.

Vamos pensar outro exemplo. Tugendhat, em suas Lições sobre ética discorda de Piaget quando este baseia a moral heterônoma sobre o respeito pela autoridade. Para ele, um dos pontos essenciais a serem pensados na relação filhos/pais não é o fato de os segundos terem autoridade sobre os primeiros, mas sim a confiança que eles despertam. 0 moral sense, condição necessária ao pensar e agir morais segundo o filósofo, teria suas raízes na confiança que as crianças desenvolvem em relação a seus progenitores e outras pessoas significativas. Nomeando o processo por meio das virtudes, teríamos o lugar importante da fidelidade: é porque os pais mostram-se fieis a seus filhos e às palavras que empenham em relação a eles que as crianças penetrariam no mundo da moral, não permanecendo no puro medo das sanções. É evidente que a fidelidade sofrerá radicais mudanças de interpretação no decorrer do desenvolvimento moral, mas o fato é que, segundo a perspectiva de Tugendhat, tal virtude encontrar-se-ia precocemente na gênese da moralidade humana.

Vamos a um último exemplo, agora retirado das pesquisas que já realizamos sobre as virtudes morais segundo as crianças (La Taille e outros, 1998). Verificamos que as crianças menores interpretam a boa-educação (polidez) como recobrindo praticamente todo o campo da moralidade, embora reconheçam que 0 castigo não se coloca para a ausência de polidez. 
Ou seja, para elas, ser bem-educado não é apenas empregar certas formas de polidez, mas também obedecer, ser justo, ser generoso, não ferir etc. Tal generalização, longe de ser apenas fruto de uma limitação cognitiva (não ter compreendido corretamente o referido conceito), também aponta, cremos, para uma característica do início da gênese da moralidade na infância. De fato, a polidez pode ser pensada em dois domínios (como definidos por Turiel). 0 primeiro é o convencional: trata-se de pequenos atos verbais que costumam ser empregados para suavizar as relações entre as pessoas, e seu efeito não pressupõe a sinceridade de quem as usa (quem fala desculpa não precisa estar ressentido para que 0 efeito de polidez seja sentido ${ }^{5}$ ). Note-se também que as formas de polidez podem mudar de cultura para cultura, uma mais formais que outras. 0 segundo domínio é o moral: o emprego da polidez traduz uma deferência em relação a outrem, um respeito. De fato, não ser polido pode, às vezes, ferir outrem, ser prova de desrespeito, de intenção de humilhação. Isto posto, nossos dados mostram que, num primeiro momento, as crianças parecem fundir os dois domínios. Por um lado, reconhecem que 0 mal-educado deve ser antes ensinado do que punido: a não-polidez não é, portanto, estritamente moral. Por outro, seus exemplos cobrem praticamente todos os atos imorais: a polidez é, portanto, também considerada como moral, fato que é confirmado com um outro dado. Quando perguntadas se podem prever quem cometeu um delito (dano material intencional), sabendo apenas que um dos dois suspeitos costuma ser mal-educado (apresentado como não empregando as pequenas frases de praxe), respondem que sim: 0 autor do delito deve ser, com grande certeza, a criança não-polida. Em resumo, somos levados a crer que a polidez ocupa uma lugar relevante no despertar da gênese da moralidade infantil. Como queria Comte-Sponville (1995), ela é a porta de entrada para as demais virtudes, a menos importante de todas, mas a primeira a ser descoberta.
Os três exemplos que demos nos serviram para defender a seguinte tese: embora algumas virtudes possam ser descartadas do sistema axiológico (definição do objeto, que pode, como em Kohlberg, privilegiar uma, a justiça), elas podem desempenhar uma papel na construção da moralidade. Referindo-se a um sistema axiomático, o direito, Piaget escreveu que

\section{é, sem dúvida, o dever do axiomático cortar 0 cordão umbilical para dissociar a construção formal de suas amarras com o real, mas cabe ao sociólogo lembrar que este cordão existiu e que seu papel foi fundamental à alimentação do direito embrionário. (1965, p.66)}

Talvez as virtudes sejam fundamentais para a alimentação da gênese da moral na criança.

12) A última forma de defendermos, do ponto de vista psicológico, a importância de estudos sobre as virtudes para compreender 0 desenvolvimento moral, decorre da abordagem que construímos e consignamos em nosso texto Vergonha, a ferida moral (La Taille, 2000). Vamos citar aqui as teses centrais deste trabalho:

- abordamos a moral na sua relação com o Eu, entendido como conjunto de representações de si (identidade);

- adotamos o critério da integração dos valores morais ao Eu como explicação da força motivacional para o pensar e agir morais;

- adotamos o critério da presença de sentimentos morais para aquilatar o lugar da moral na personalidade, entendida como sistema;

- a tomada de consciência de si representativa é contemporânea da consciência da própria perceptibilidade e as representações de

5. Quemfala desculpa (des-culpa) não precisa estar sentindo culpa. 
si decorrentes de tal tomada de consciência são sempre valorativas;

- a busca de representações de si positivas é a uma das motivações básicas das condutas humanas;

- tais representações de si estão, na sua gênese e manutenção, vinculadas aos juízos alheios, porém tal vínculo não implica sua total dependência a esses juízos: há um constante embate entre as imagens que a pessoa tem de si e os juízos positivos e negativos de outrem, o julgar-se interage com o ser julgado;

- sentimento de vergonha aparece como fundamental para a presente perspectiva teórica uma vez que, com a exceção da "vergonha de exposição": 1) implica num auto-juízo negativo doloroso (dor decorrente da incessante busca de representações de si de valor positivo); 2) diz respeito ao "ser", portanto às representações de si; e, 3) embora ocorra em decorrência de alguma "falha", real ou antecipada, moral ou não, sua presença pode ser vista como sinal de valor por parte de quem o experimenta;

- tal fato é sobretudo notado no âmbito da vergonha decorrente de uma falha moral (La Taille, 2000, p. 70).

A representações de si, como exposto acima, são sempre valorativas. Ora, podem então acontecer vários cenários.

Num deles, o indivíduo associa sobretudo às representações que tem de si valores que não são morais, como a beleza física, a posse do dinheiro, o status social etc. Quando tais valores constituem as representações de si, falamos em auto-estima. E falamos em auto-respei to justamente quando tais valores são morais. É um possível segundo cenário: o indivíduo se vê como essencialmente ético. Dito de outra forma, neste cenário ser "eu" e ser moral é equivalente (daí a vergonha retrospectiva quando se comete algo que fere a ética e a vergonha prospectiva quando se antecipa a possibilidade da transgressão - ver Harkot-de- La-Taille, 1999).
Se definirmos moral como apenas atinente à virtude justiça, o auto-respeito será apenas efetivado quando a pessoa realizar ações justas ou se abster de atos injustos (no sentido em que ferem direitos humanos alheios). Porém, se aceitarmos considerar as virtudes generosidade, gratidão, compaixão e outras como morais, o auto-respeito poderá receber uma definição ampliada.

Dois novos cenários devem então ser pensados. Num, a pessoa coloca no núcleo das representações de si virtudes altruístas. Retomando a tese de Gilligan, algumas pessoas poderão se ver como essencialmente generosas e, assim, cumprir a pauta de uma ética do cuidado; e outras poderão se ver como principalmente justas e agirem segundo a ética da justiça. Noutro cenário, as coisas se complicam do ponto de vista ético. Imaginemos alguém cujas representações de si incluem, em lugar privilegiado, a virtude coragem, mas que tal virtude esteja associada não à justiça social, mas sim à violência. Como previsto no quadro teórico colocado acima, tal pessoa sentirá vergonha se não conseguir concretizar a boa imagem que se associa à coragem e, sendo ela vista como força, virilidade e agressão, a presença dessa virtude dentro das representações de si terá o ef eito de afastar o indivíduo da moral. Raciocínio semelhante pode ser feito com a virtude fidelidade: se tal virtude for entendida como revestindo um valor absoluto, a pessoa poderá até cometer atos injustos para se manter fiel a contratos passados com certas pessoas do grupo. E poderíamos multiplicar os exemplos.

0 que deve ser ressaltado a partir deste último cenário hipotético é que as virtudes (ou pelo menos algumas), dependendo da interpretação ética que a elas se dê e do lugar que, enquanto valor, ocupam nas representações de si, podem se transformar em fatores complicadores do pensar e agir morais. Ora, tal possibilidade deve ser levada em conta, notadamente na educação. Será que algumas crianças (e 
também adultos), embora saibam que o que fazem fere a ética, ainda assim o fazem por que, aos próprios olhos e aos olhos do grupo, é uma prova de coragem ou fidelidade? Na gênese da moralidade, as virtudes podem ser fortes aliadas (como visto em 10 e 11), mas também podem ser fortes adversárias. Eis uma razão a mais para nos debruçarmos sobre elas.

\section{Referências bibliográficas}

ADLER, A. Le tempérament nerveux. Paris: Payot, 1912/1992.

ADORNO, T.W. La personalidad autoritária. Buenos Aires: Proyección, 1950.

ARISTOTE. Éthique de Nicomaque. Paris: Flamarion, 1965.

COMTE-SPONVILLE, A. Petit traité des grandes vertus. Paris: PUF, 1995.

FLANAGAN, O. Psychologie morale et éthique. Paris: PUF, 1996.

GILLIGAN. C. Uma voz diferente. Rio de J aneiro: Rosa dos Ventos, 1982.

GILLIGAN. C. Remaping the moral domain: new images of self and relationship. In: Havard: University Press, 1988.

HARKOT-DE-LA-TAILLE, E. Ensaio semiótico sobre a vergonha. São Paulo: Humanitas, 1999.

KANT, E. Métaphysique des moeurs, deuxième partie: doctrine des vertus. Paris: Vrin, 1985 [1797].

KOHLBERG, L. Essays on moral development. S. Francisco: Harper \& Row, 1981.

LA TAILLE, Y. de. Vergonha, a ferida moral. São Paulo; 2000. Tese (Livre-Docência) - Instituto de Psicologia da USP.

LA TAILLE, Y. MICELLI, A., DOM INGUES, C., KRAVOSAC, D., J AMRA, F., FIORINI, F., BRONSTEIN, M., NETO, S. As virtudes morais segundo as crianças 1. São Paulo: Instituto de Psicologia USP (Relatório Científico FAPESP), 1998.

PERRON, R. Les représentations de soi. Toulouse: Privat. 1991.

PIAGET, J . Le jugement moral chez l'enfant. Paris, PUF: 1932/1992. Études sociologiques. Paris: Droz, 1965.

SENNETT, R. A corrosão do caráter. Rio de J aneiro: Record, 1999.

TAYLOR, C. Les sources du moi. Paris: Seuil, 1998.

TUGENDHAT. E. Lições sobre ética. Rio de J aneiro: Vozes, 1993.

TURIEL, E. The development of social knowledge: morality and convention. Cambridge: Cambridge University Press, 1993.

Recebido em 16.04.01

Aprovado em 07.06 .01

Yves de La Taille é livre-docente junto ao Departamento de Psicologia da Aprendizagem, do Desenvolvimento e da Personalidade do Instituto de Psicologia da USP. Autor de várias obras, dentre elas Limites: três dimensões educacionais (Ática). 